\title{
Muckle-Wells syndrome
}

INSERM

\section{Source}

INSERM. (1999). Orphanet: an online rare disease and orphan drug data base. MuckleWells syndrome. ORPHA:575

Muckle-Wells syndrome (MWS) is an intermediate form of cryopyrin-associated periodic syndrome (CAPS; see this term) and is characterized by recurrent fever (with malaise and chills), recurrent urticaria-like skin rash, sensorineural deafness, general signs of inflammation (eye redness, headaches, arthralgia/myalgia) and potentially lifethreatening secondary amyloidosis (AA type). 